\title{
Paraesthesia in Regional Anaesthesia
}

\author{
Bouman Esther, Gramke Hans-Fritz and Marcus A. Marco \\ Department of Anaesthesiology and Pain Treatment, \\ Maastricht University Medical Centre+, Maastricht, \\ The Netherlands
}

\section{Introduction}

Paraesthesia is commonly defined as an abnormal altered sensation ranging from numbness, to burning, tingling or continual pain (Garisto et al. 2010). In regional anaesthesia there should also be "neural" quality as introduction of a needle can induce other causes of pain e.g. skin, tissue or bone contact. So the definition is slightly modified to a burning, shooting or electric sensation or pain usually radiating periferically e.g. to arms, legs or buttocks (Aldrete 2003; Pong et al. 2009).

The aetiology of paraesthesia related to regional anaesthesia is not fully understood. Direct trauma to nerves, local haemorrhage, hydrostatic pressure and neurotoxicity from the local anaesthetic or other injected substances like preservatives and anti-microbial additives may all play a part in the spectrum (Aldrete 2003; Garisto et al. 2010).

During the performance of regional anaesthesia paraesthesia is a frequently reported phenomenon. In the context of paraesthesia two modalities of regional anaesthesia have to be discussed, i.e. the peripheral nerve or conduction block and neuraxial procedures. Both have their own specific clinical indications, applications and complications. Pathophysiology of peripheral nerve injury and spinal cord injury is very similar. However due to the difference in anatomical considerations and applied techniques it will be discussed separately.

\section{Peripheral nerve blocks}

Peripheral nerve blocks are used to anaesthetize a part of the body, to avoid or complement general anaesthesia and to benefit from good pain relief postoperatively. They can be used for a wide range of unilateral procedures localized a limited body area varying from local eye blocks to regional anaesthesia of upper or lower extremities and even a block of the abdominal wall is possible. These nerve blocks can be performed at any level in the course of a peripheral nerve e.g. the radial nerve can be anaesthetized at the level of the brachial plexus, the elbow or at the wrist, separately or in adjunct to general anaesthesia. Currently there is an increased interest in all kind of new techniques e.g. transverse abdominus plain (TAP), ilioinguinal, iliohypogastric, lumbar plexus, psoas and paravertebral blocks and the continuous use of peripheral nerve catheters in the ambulatory setting is advocated (Lee et al. 2011). Nerve blocks for chronic pain treatment are beyond the scope of this chapter. 


\subsection{Techniques and approaches localizing peripheral nerves}

There are several techniques to localize peripheral nerves: blind techniques, fascial pops, eliciting paraesthesia, trans- and peri-vascular approaches, electrical nerve stimulation, ultrasound/ ultrasonography with or without electrical nerve stimulation, computer tomography (CT) and magnetic resonance imaging (MRI). The first mentioned techniques are frequently used, however in daily clinical practice CT and MRI are nor practically nor workable in the care of the patient (Wedel 2008).

In earlier times elicting paraesthesia was the only way to localize a nerve to perform a peripheral conduction block. Currently more sophisticated techniques are available to clinical practice. Electrical nerve stimulation to elict a motor response of a peripheral nerve is commonly used. However, both techniques are depending on anatomical landmarks and so essentially blind with regard to the nerve itself. The required proximity of the needle to the intended nerve is accompanied by the risk of nerve contact, puncture and damage of related structures. With the use of ultrasound techniques are not blind anymore. Nerves, muscles, blood vessels, pleura and even the spread of local anaesthetic peri-neurally can be visualised (Jeng \& Rosenblatt 2011; Marhofer et al. 2010). This does not imply that these techniques are without complications. Although none of the patients suffered from postoperative neurological complications an incidence of unintentional intraneural injection of $17 \%$ was reported for ultrasound guided interscalene and supraclavicular nerve blocks (Liu et al. 2011).

There are no safety data available to support one of the mentioned techniques (Chin \& Handoll 2011) No technique is proven superior regarding safety and efficacy results are inconsistent (Horlocker 2010). However ultrasounds block peripheral nerve localization showed improved efficacy compared to electrical nerve stimulation techniques in several systematic reviews (Abrahams et al. 2009; Neal, J. M. et al. 2008).

\subsection{Paraesthesia and peripheral nerve injury}

Fortunately serious neurological complications associated with regional anaesthesia are rare. But this makes it difficult to obtain reliable data about the actual incidence of peripheral nerve block related neurological symptoms. Recent prospective studies reported an incidence of postoperative neurological symptoms between $8-11 \%$ direct postoperatively to $0.6 \%$ at 6 months (Fredrickson \& Kilfoyle 2009; Liu et al. 2009). The majority of the patients reported transient neurological symptoms varying from tingling to paraesthesia resolving between a few days and several months. In France 2.4 serious injuries per 10.000 peripheral nerve blocks were reported (Auroy et al. 2002) It was noted that in case of serious injury or severe neurological complications, they were often related to paraesthesia during needle insertion or pain during injection of the local anesthetics (Auroy et al. 1997). Though permanent neurological injury after a peripheral nerve block is rare neuropathy was reported < 3:100 (Brull et al. 2007). Recently a prospective Australian audit of more than 7000 peripheral nerve and plexus blocks showed and incidence of 0.4 block related nerve injuries per 1000 blocks (Barrington et al. 2009).

\subsection{Risk factors for peripheral nerve injury}

Risk factors known to be involved in peripheral nerve injury can be divided into patient related, block related and surgery related risk factors. 


\subsubsection{Patient related risk factors}

In general patients who already suffer from medical conditions that affect nerve conduction like multiple sclerosis, diabetic neuropathy, spinal stenosis and lumbar root disease, neurotoxic chemotherapy and patients with peripheral vascular disease are more susceptible to peripheral nerve block related complications. This could be due to increased sensitivity of already damaged nerves or altered blood supply (Horlocker 2010; Jeng et al. 2010). Furthermore some of the patients e.g. obese, pregnant and patients that use potent anti-coagulants are more prone to procedure related technical problems, haematoma and multiple attempts (Brull et al. 2007; Watts \& Sharma 2007), which are associated with peripheral nerve injury.

\subsubsection{Block related risk factors}

Data from the ASA closed claims projects (Lee et al. 2011) show that upper extremity blocks are more associated with claims regarding nerve injuries. The most performed types of peripheral blocks were interscalene and axillary nerve blocks and intravenous regional anaesthesia. The interscalene and axillary blocks were responsible for the majority of the claims (42\% and $26 \%$ respectively) (Lee et al. 2011). The brachial plexus was most frequently involved (32\%) followed by the median nerve $(21 \%)$, ulnar nerve $(16 \%)$, spinal cord $(8 \%)$ and the phrenic nerve $(8 \%)$ (Lee et al. 2011). One third of these injuries was permanent and /or disabling (Lee et al. 2011). Spinal cord injuries were all associated with permanent damage and were more frequently related with interscalene blocks under general anesthesia. In $68 \%$ of the claims for nerve injury it was designated as block related. (Lee et al. 2011)

\subsubsection{Surgery related risk factors}

Surgery related risk factors are ill-defined. However there is an association with trauma. Symptoms can be fracture related e.g. radial nerve injury in proximal humerus fractures or cranial nerve injury after Le Fort I osteotomy (Kim et al. 2011). Furthermore nerve injury is associated with the use of surgical instruments, diathermy, stretch, nerve compression, ischemia, the use of a tourniquet, patient positioning e.g. lithotomy position and peripheral nerve protection. However in what extent which factor contributes to nerve damage is uncertain (Liguori 2004; Watts \& Sharma 2007)

\subsection{Pathophysiology of peripheral nerve injury}

Several mechanisms of nerve injury following surgery under peripheral nerve block have been proposed and described but their relative significance is unknown (Hogan 2008; Liguori 2004).

\subsubsection{Neurotoxicity}

In cell cultures local anaesthetics in clinically used concentrations cause cytotoxic effects like inhibition of cell growth, necrosis and apoptosis (Hogan 2008). Furthermore local anaesthetics may cause neural membrane lysis due to detergent properties (Kitagawa et al. 2004). The size of these effects is strongly influenced by a prolonged duration of exposure 
and higher concentration of the local anaesthetics, with in vitro the lowest neurotoxicty for procaine, mepivacaine and lidocaïne compared with ropivacaine and bupivacaine (Hogan 2008; Perez-Castro et al. 2009), however most clinical relevant toxicity is attributed to high concentrations of lidocaïne (Zink \& Graf 2003).

In a sciatic nerve rat model direct application of 3\% 2-chloroprocaine or 1\% tetracaine, but not $2 \%$ lidocaïne or $0.75 \%$ bupivacaine resulted in subperineural and endoneural oedema, with mast cell degranulation, proliferation of endoneural fibroblasts, Schwann cell necrosis and axonal dystrophy (Myers et al. 1986). Animal data suggest moreover that amino-ester agents like procaine and tetracaine are more neurotoxic than amino-amide agents like lidocaïne and bupivacaine (Zink \& Graf 2003).

Other adjuvants injected together with the local anaesthetic e.g. anti-microbial preservatives added to multi-use vials, anti-oxidants or addition of epinephrine or bicarbonate, may also cause nerve damage (Hogan 2008; Zink \& Graf 2003).

\subsubsection{Mechanical nerve damage}

Nerve injury from nerve contact or penetration is more likely to result due to sharp-bevelled needles than to blunt bevelled needles. However needle-tip penetration is not always the cause of nerve injury. Penetration of fascicles with or without infusion of saline did not result in changes in microscopy or alterations of diffusion barriers, despite high infusion pressures (Hogan 2008). But nerves are not homogenous structures so it is possible to penetrate a nerve without reaching and damaging a neuronal structure.

High injection pressures moreover are associated with persistent neurological deficits after intra neural injections indicating that the surrounding perineurium is very important to protect the fascicles from the cytotoxic effects of the local anaesthetics (Hogan 2008; Jeng \& Rosenblatt 2011).

It remains unclear whether a block technique to elict paraesthesia increases the risk of peripheral nerve injury (Horlocker 2001). Nevertheless peripheral nerve damage remains associated with injection of local anaesthetic and paraesthesia or pain on injection of a local anaesthetic (Auroy et al. 2002; Hogan 2008).

Other mechanisms of mechanical nerve damage include surgical trauma, peri- and postoperative positioning and damage from tourniquets. If the latter is a result of ischemia or mechanical deformation is unclear. However by compression of the nerve under the edge of a pneumatic cuff substantial distortion of myelin lamellae and axonal shrinkage is reported as early as 2-4 hours after tourniquet inflation (Hogan 2008; Liguori 2004).

\subsubsection{Ischemia}

The earliest response to ischemia of a peripheral neuron is depolarisation and spontaneous activity, perceived by the patient as paraesthesia. Nerve function is restored completely after ischemia of less than 2 hours and ischemic periods to up to 6 hours failed to produce permanent structural nerve changes. However histological examination showed oedema and fiber degeneration (Hogan 2008). Ischemic injury may result from pressure and volume of the local anesthetic or added vasoconstrictors. Moreover local anaesthetics like lidocaïne 
and bupivacaine decrease neuronal blood flow. However contribution of vasoconstriction to peripheral nerve injury has not been proved (Hogan 2008).

Haematoma and vascular injury are difficult to classify as they may cause local ischemia but may provoke local high pressures as well (Liguori 2004).

\subsection{Diagnosis and management of peripheral nerve injury}

The best treatment of neurological deficit is prevention and starts with a good pre-operative preparation and complete documentation of the block. This includes information about the pre-existent condition of the patient, concomitant diseases, used techniques, local anaesthetics and adjuvants used, complications or difficulties during the procedure, the efficacy and the duration of the block and the surgical procedure. Direct postoperative follow-up should be performed in all patients. If symptoms occur careful physical examinations should be performed and an expert e.g. neurologist should be consulted. Electrophysiological testing should be performed to define a neurogenic basis of nerve damage, to localize the site of injury and to define the severity of the injury.

If compression is suspected ultrasonography or an MRI of the plexus has to be done. (Borgeat 2005; Mayfield 2005; Neal, J. M. et al. 2008)

\section{Neuraxial block}

Neuraxial blocks are applied to induce anaesthesia or analgesia in a limited part of the body. Especially patients scheduled for major thoracic or abdominal procedures or procedures in the lower extremities or pelvis can benefit from these techniques.

There are 3 techniques to provide neuraxial blockade: Spinal, epidural and a combination of both for longer lasting analgesia i.e. combined spinal-epidural anaesthesia (CSE) as a needle through needle procedure or with the insertion of a catheter at a different level (Warren 2008).

Spinal or dural anaesthesia implies perforation of the dura and arachnoid matter, and after aspiration of cerebrospinal fluid, injection of local anaesthetic. Whereas in epidural anaesthesia the dura remains intact. Spinal anaesthesia is restricted to the lumbar region due to the presence of the conus medullaris at the level of L1-L2 in the adult, but a wide variation exists between as high as T12 to as low as L4. Especially in patients with difficult surface landmarks these anatomical variations can lead to more cephalad needle placement than intended (Neal, J.M 2008). However recently experimental higher spinal techniques are described in literature (van Zundert et al. 2007).

The epidural space can be accessed at any level up to $C 7$ to induce a segmental anaesthetic block depending on the site of injection of local anaesthetics (Warren 2008). The technique relies on anatomical landmarks for penetration of the ligamentum flavum to localize the epidural space. The ligamentum flavum however fuses not always in the midline, especially in the upper thoracic en cervical levels. Moreover the depth of the epidural space itself decreases from 5-8 $\mathrm{mm}$ in the lumbar region to $1-2 \mathrm{~mm}$ in the upper thoracic and cervical regions (Neal, J.M 2008). 


\subsection{Paraesthesia and the neuraxial block}

In contrast to the peripheral conduction block elicting paraesthesia for neuraxial block is never aimed for. As there are no nerve roots in the posterior epidural space the occurrence of paraesthesia implies perforation of the dural sac with direct contact or puncture of the spinal cord, intrathecal contact with nerve roots, or, more frequently, extradurally contact with an exciting nerve root. Paraesthesia usually does not lead to neurological sequelae but is an unpleasant sensation for the patient and the significance still remains unclear (Aldrete 2003; Neal, J.M 2008).

\subsection{Paraesthesia and spinal, epidural and combined spinal epidural anaesthesia}

Reported incidences of paraesthesia vary between 0.2 and $56 \%$ depending on approach (Leeda et al. 2005), patient characteristics (Hebl et al. 2010; Spiegel et al. 2009), technique (Hebl et al. 2006; McAndrew \& Harms 2003; van den Berg et al. 2011), different catheters (Bouman et al. 2007; Jaime et al. 2000)and depth of insertion (Cartagena \& Gaiser 2005). Even an incidence as high as $81 \%-89 \%$ was reported (Hetherington et al. 1994; van den Berg et al. 2005).

The symptoms of paraesthesia during conduct of neuraxial anaesthesia are frequently mild and transient. However sometimes they are so intense that the procedure must be aborted. Fortunately the incidence of permanent neurological damage of 1:20.000-30.000 for spinal anaesthesia and 1:25.000 for obstetric epidurals and 1:3600 in other epidurals remains low (Moen et al. 2004), but in France two thirds of the patients with neurological deficits reported paraesthesia during needle placement or pain on injectionof local anaesthetics (Auroy et al. 1997).

Moreover it seems that paraesthesia is like pre-existing neurological disease, degenerative spinal disease, obesity, female sex and anti-coagulation a risk factor for or an indicator of a complicated procedure and therefore for permanent neurological injury (Aldrete 2003; Brull et al. 2007; Fowler 2007).

\subsection{Transient neurological symptoms}

Transient neurological symptoms (TNS) were first reported in 1993. After an uneventful spinal anaesthesia and after full recovery, within a few hours symptoms of light to severe pain in the gluteal region (buttocks) radiating to both lower extremities start with a duration of 6 hours up to 5 days. Furthermore no abnormalities on neurological examination, MRI or electrophysiological testing should be demonstrated (Pollock 2003; Zaric \& Pace 2009).

The highest incidences of TNS are found in patients with intrathecal lidocaïne undergoing surgery in lithotomy position (30-36\%), arthroscopic knee surgery (18-22\%), while in patients undergoing other surgery in supine position the incidences are 4-8\% (Pollock 2003).

Although interpreted as possible neurotoxicity of lidocaine TNS is associated with all other local anaesthetics however in a lower incidence (Zaric \& Pace 2009). Decreasing lidocaïne concentration from 5 to $0.5 \%$ does not decrease the incidence of TNS. Glucose, hyperbaricity and hyperosmolarity are not contributing factors (Pollock 2003). 
Other possible causes are direct needle trauma, neural ischemia secondary to sciatic stretching, patient positioning, pooling of local anaesthetics, muscle spasm, early mobilization and irritation of the dorsal root ganglion (Pollock 2003).

Treatment can be very difficult. In general non-steroidal anti-inflammatory drugs are prescribed; occasionally opioids are necessary to treat the symptoms. Prevention is essential as treatment is not always successful. If neurological examination is abnormal other possible complications have to be ruled out e.g. epidural haematoma or nerve root damage (Pollock 2003).

\subsection{Serious neurological complications}

Although rare, if neurological deficits occur serious complications have to be ruled out. Most cases of spinal haematoma are characterized by an acute or subacute course with acute onset of pain at the level of the haemorrhage with more or less severe paralysis with or without bladder/intestinal disturbances (Kreppel et al. 2003).

Direct neurological or neurosurgical consultation, MRI and neurophysiolocal testing is required because possible treatment options. Decompressive laminectomy for epidural haematoma, antibiotics and possible surgical drainage for epidural abscess and meningitis, hypertensive therapy for anterior spinal artery syndrome are necessary to reduce morbidity.

A decompressive laminectomy should be done within 6-8 hours after start of the symptoms to avoid permanent spinal cord injury (Kreppel et al. 2003; Neal, J. M. et al. 2008). For spinal nerve injury, adhesive arachnoiditis and cauda equine syndrome no effective treatment is available (Naguib et al. 1998; Pollock 2003).

Epidural abscess and meningitis are not further discussed as there no obvious relation with paraesthesia.

\subsection{Pathophysiology of spinal cord, spinal root and spinal nerve injury}

Like peripheral nerve injury spinal cord and spinal root injury after the conduct of a neuraxial block has several proposed mechanisms. Sometimes the mechanism is obvious like in case of epidural haematoma, but often the cause of spinal cord injury remains unclear of multifactorial.

\subsubsection{Mechanical injury of the spinal cord and spinal nerve damage}

Mechanical injury of the spinal cord and spinal nerves during of after conduct of a neuraxial block can be caused by several mechanisms.

The vertebral column protects spinal cord and spinal nerves to mechanical injury. To perform a neuraxial block it is necessary to precisely avoid this defence. The access to the spinal canal is based on landmark techniques, but ultrasound becomes more common practice (Balki 2010; Perlas 2010). However as earlier indicated human anatomy varies and this can lead to failure to contact identifiable landmarks, unintentional cephalad needle placement, and unintentional penetration of the dura. 
Penetration of the spinal cord can provoke intense pain, pressure or paraesthesia or no sensation at all. After penetration of the spinal cord, damage can occur from injury of neural structures, haematoma, oedema, central syrinx creation, local anaesthetic or adjuvant toxicity or a combination of these factors (Neal, J.M 2008).

Furthermore reduction of the vertebral canal diameter by degenerative changes, intra- and extradural mass lesions e.g. haematoma, and patient positioning may compromise spinal cord blood flow. This by increasing spinal cord or CSF pressure, decreasing arterial inflow and venous outflow leading to spinal cord ischemia, possibly worsened by injected or infused local anaesthetic (Neal, J.M 2008).

\subsubsection{Vascular injury}

The spinal cord and cauda equine receive two thirds of their blood supply from the anterior spinal artery (ASA). The lower thoracic and lumbar sacral spinal cord are supplied by the arteria radicularis magna or artery of Adamkiewicz which provides $25-50 \%$ of the total spinal cord blood flow (Biglioli et al. 2004; Neal, J.M 2008). Spinal cord blood flow is like the cerebral blood flow auto regulated with mean arterial pressures between 50/60 - $120 \mathrm{mmHg}$ in animal models and hypoperfusion with hypo perfusion is an often suggested cause of spinal cord damage. However in patients undergoing spine surgery prolonged periods of hypotension induced no detectable spinal cord injury, nor is anterior spinal artery syndrome associated with cardiopulmonary bypass or induced hypotension. Nevertheless the diagnosis anterior spinal artery syndrome has been made in cases with unexplained injury associated with neuraxial blocks. Underlying medical conditions like atherosclerosis are more probable explanations than hypotension or vasoactive agents (Neal, J.M 2008).

Direct vascular trauma from midline and paramedian approaches is anatomically unlikely, but possible during lateral or peri-spinal approaches as psoas compartment or celiac plexus blocks, but no human data supports this view (Neal, J.M 2008).

\subsubsection{Neurotoxicity}

As earlier mentioned all local anaesthetics have the potential of neurotoxicity. However in clinically used doses local anaesthetics, opioids, adjuvants and preservatives are relatively safe (Hodgson et al. 1999). However after disruption of the blood-spinal cord barrier certain anatomic conditions may contribute to increased susceptibility to injury. The cauda equina consists of partly unmyelinated nerve fibres with a relative high surface area which is exposed to potentially neurotoxic agents. Secondly, nerve roots in the blood-spinal cord barrier lack connective tissue which provides mechanical and metabolic protection compared with peripheral nerves. Furthermore clearance of toxic substances by CSF is not as efficient as vascular clearance which causes spinal cord and spinal nerve roots to be exposed to drug maldistribution and local high drug doses. These factors are believed to have contributed to cases with cauda equina syndrome after spinal anaesthesia with micro catheters (Neal, J.M 2008).

\section{Conclusions}

During the conduct of regional anaesthesia paraesthesia is a frequently reported phenomenon. It is a risk factor for or an identifier of a complicated procedure and in such a way for 
permanent neurological injury. Other risk factors are patient, procedure or block related. Possible causes of neurological injury are mechanical, vascular or ischemia and neurotoxicity.

Although rare, if neurological deficits occur serious complications have to be ruled out, by neurological or neurosurgical consultation, and neurophysiolocal testing. This because possible treatment options have to be enforced as soon as possible to minimize morbidity. MRI is the preferred mode of imaging to demonstrate spinal canal pathology. The best treatment of neurological deficit is prevention and starts with a good pre-operative preparation and complete documentation of the block.

\section{Acknowledgements}

The authors would like to thank Mrs. Resy VanderBroeck for her valuable comments and preparation of the manuscript.

\section{References}

Abrahams, M.S., M.F. Aziz, R.F. Fu \& J.L. Horn (2009). "Ultrasound guidance compared with electrical neurostimulation for peripheral nerve block: a systematic review and meta-analysis of randomized controlled trials." Br J Anaesth 1023 (3Mar): 408417

Aldrete, J.A. (2003). "Neurologic deficits and arachnoiditis following neuroaxial anesthesia." Acta Anaesthesiol Scand 471 (1Jan): 3-12

Auroy, Y., D. Benhamou, L. Bargues, C. Ecoffey, B. Falissard, F.J. Mercier, H. Bouaziz \& K. Samii (2002). "Major complications of regional anesthesia in France: The SOS Regional Anesthesia Hotline Service." Anesthesiology 975 (5Nov): 1274-1280

Auroy, Y., P. Narchi, A. Messiah, L. Litt, B. Rouvier \& K. Samii (1997). "Serious complications related to regional anesthesia: results of a prospective survey in France." Anesthesiology 873 (3: 479-486

Balki, M. (2010). "Locating the epidural space in obstetric patients-ultrasound a useful tool: continuing professional development." Can J Anaesth 5712 (12Dec): 1111-1126

Barrington, M.J., S.A. Watts, S.R. Gledhill, R.D. Thomas, S.A. Said, G.L. Snyder, V.S. Tay \& K. Jamrozik (2009). "Preliminary results of the Australasian Regional Anaesthesia Collaboration: a prospective audit of more than 7000 peripheral nerve and plexus blocks for neurologic and other complications." Reg Anesth Pain Med 346 (6NovDec): 534-541

Biglioli, P., M. Roberto, A. Cannata, A. Parolari, A. Fumero, F. Grillo, M. Maggioni, G. Coggi \& R. Spirito (2004). "Upper and lower spinal cord blood supply: the continuity of the anterior spinal artery and the relevance of the lumbar arteries." J Thorac Cardiovasc Surg 1274 (4Apr): 1188-1192

Borgeat, A. (2005). "Neurologic deficit after peripheral nerve block: what to do?" Minerva Anestesiol 716 (6Jun): 353-355

Bouman, E.A., H.F. Gramke, N. Wetzel, T.H. Vanderbroeck,R. Bruinsma,M. Theunissen,H.E. Kerkkamp \& M.A. Marcus (2007). "Evaluation of two different epidural catheters in clinical practice. narrowing down the incidence of paresthesia!" Acta Anaesthesiol Belg 582 (2: 101-105 
Brull, R., C.J. McCartney, V.W. Chan \& H. El-Beheiry (2007). "Neurological complications after regional anesthesia: contemporary estimates of risk." Anesth Analg 1044 (4Apr): 965-974

Cartagena, R. \& R.R. Gaiser (2005). "Advancing an epidural catheter $10 \mathrm{~cm}$ then retracting it $5 \mathrm{~cm}$ is no more effective than advancing it $5 \mathrm{~cm}$." Journal of clinical anesthesia 177 (72005/11): 528-530

Chin, K.J. \& H.H. Handoll (2011). "Single, double or multiple-injection techniques for axillary brachial plexus block for hand, wrist or forearm surgery in adults." Cochrane Database Syst Rev 7: CD003842

Fowler, S.J. (2007). "Risk of a severe neurological complication after regional anesthesia should be individualized." Anesth Analg 1053 (3Sep): 880-881; author reply 881

Fredrickson, M.J. \& D.H. Kilfoyle (2009). "Neurological complication analysis of 1000 ultrasound guided peripheral nerve blocks for elective orthopaedic surgery: a prospective study." Anaesthesia 648 (8Aug): 836-844

Garisto, G.A., A.S. Gaffen, H.P. Lawrence, H.C. Tenenbaum \& D.A. Haas (2010). Occurrence of Paresthesia After Dental Local Anesthetic Administration in the United States. 141: 836-844.

Hebl, J.R., T.T. Horlocker, S.L. Kopp \& D.R. Schroeder (2010). "Neuraxial blockade in patients with preexisting spinal stenosis, lumbar disk disease, or prior spine surgery: efficacy and neurologic complications." Anesth Analg 1116 (6Dec): 15111519

Hebl, J.R., S.L. Kopp, D.R. Schroeder \& T.T. Horlocker (2006). "Neurologic complications after neuraxial anesthesia or analgesia in patients with preexisting peripheral sensorimotor neuropathy or diabetic polyneuropathy." Anesth Analg 1035 (5Nov): 1294-1299

Hetherington, R., R.A. Stevens, J.L. White, L. Spitzer \& S. Koppel (1994). "Subjective experiences of anesthesiologists undergoing epidural anesthesia." Reg Anesth. 194 (4: 284-288.

Hodgson, P.S., J.M. Neal, J.E. Pollock \& S.S. Liu (1999). "The neurotoxicity of drugs given intrathecally (spinal)." Anesth Analg 884 (4Apr): 797-809

Hogan, Q.H. (2008). "Pathophysiology of peripheral nerve injury during regional anesthesia." Reg Anesth Pain Med 335 (5Sep-Oct): 435-441

Horlocker, T.T. (2001). "Neurologic complications of neuraxial and peripheral blockade." Canadian Journal of Anesthesia 48S1 (S1: R72-76

Horlocker, T.T. (2010). "Complications of regional anesthesia." European Journal of Pain Supplements 44 (4: 227-234

Jaime, F., G.L. Mandell, M.C. Vallejo \& S. Ramanathan (2000). "Uniport soft-tip, open-ended catheters versus multiport firm-tipped close-ended catheters for epidural labor analgesia: a quality assurance study." J Clin Anesth 122 (2Mar): 89-93

Jeng, C.L. \& M.A. Rosenblatt (2011). "Intraneural injections and regional anesthesia: the known and the unknown." Minerva Anestesiol 771 (1Jan): 54-58

Jeng, C.L., T.M. Torrillo \& M.A. Rosenblatt (2010). "Complications of peripheral nerve blocks." Br J Anaesth 105 Suppl 1Dec): i97-107

Kim, J.W., B.R. Chin, H.S. Park, S.H. Lee \& T.G. Kwon (2011). "Cranial nerve injury after Le Fort I osteotomy." Int J Oral Maxillofac Surg 403 (3Mar): 327-329 
Kitagawa, N., M. Oda \& T. Totoki (2004). "Possible mechanism of irreversible nerve injury caused by local anesthetics: detergent properties of local anesthetics and membrane disruption." Anesthesiology 1004 (4Apr): 962-967

Kreppel, D., G. Antoniadis \& W. Seeling (2003). "Spinal hematoma: a literature survey with meta-analysis of 613 patients." Neurosurg Rev 261 (1Jan): 1-49

Lee, L.A., K.L. Posner, C.D. Kent \& K.B. Domino (2011). "Complications Associated With Peripheral Nerve Blocks: Lessons From the ASA Closed Claims Project." Int Anesthesiol Clin 493 (3Summer): 56-67

Leeda, M.,R. Stienstra, M.S. Arbous, A. Dahan, B. Th Veering, A.G. Burm \& J.W. Van Kleef (2005). "Lumbar epidural catheter insertion: the midline vs. the paramedian approach." Eur J Anaesthesiol 2211 (11Nov): 839-842

Liguori, G.A. (2004). "Complications of regional anesthesia: nerve injury and peripheral neural blockade." J Neurosurg Anesthesiol 161 (1Jan): 84-86

Liu, S.S., J.T. YaDeau, P.M. Shaw, S. Wilfred, T. Shetty \& M. Gordon (2011). "Incidence of unintentional intraneural injection and postoperative neurological complications with ultrasound-guided interscalene and supraclavicular nerve blocks." Anaesthesia 663 (3Mar): 168-174

Liu, S.S., V.M. Zayas, M.A. Gordon, J.C. Beathe, D.B. Maalouf, L. Paroli, G.A. Liguori, J. Ortiz, V. Buschiazzo, J. Ngeow, T. Shetty \& J.T. Ya Deau (2009). "A prospective, randomized, controlled trial comparing ultrasound versus nerve stimulator guidance for interscalene block for ambulatory shoulder surgery for postoperative neurological symptoms." Anesth Analg 1091 (1Jul): 265-271

Marhofer, P., H. Willschke \& S. Kettner (2010). "Current concepts and future trends in ultrasound-guided regional anesthesia." Curr Opin Anaesthesiol 235 (5Oct): 632-636

Mayfield, J.B. (2005). "Diagnosis and management of peripheral nerve block complications." Int Anesthesiol Clin 433 (3Summer): 119-126

McAndrew, C.R. \& P. Harms (2003). "Paraesthesiae during needle-through-needle combined spinal epidural versus single-shot spinal for elective caesarean section." Anaesthesia and intensive care 315 (5Oct): 514-517

Moen, V., N. Dahlgren \& L. Irestedt (2004). "Severe neurological complications after central neuraxial blockades in Sweden 1990-1999." Anesthesiology 1014 (4Oct): 950-959

Myers, R.R., M.W. Kalichman, L.S. Reisner \& H.C. Powell (1986). "Neurotoxicity of local anesthetics: altered perineurial permeability, edema, and nerve fiber injury." Anesthesiology 641 (1Jan): 29-35

Naguib, M., M.M. Magboul, A.H. Samarkandi \& M. Attia (1998). "Adverse effects and drug interactions associated with local and regional anaesthesia." Drug Saf 184 (4Apr): 221-250

Neal, J.M. (2008). "Anatomy and pathophysiology of spinal cord injury associated with regional anesthesia and pain medicine." Reg Anesth Pain Med 335 (5Sep-Oct): 423434

Neal, J.M., C.M. Bernards, A. Hadzic, J.R. Hebl, Q.H. Hogan, T.T. Horlocker, L.A. Lee, J.P. Rathmell, E.J. Sorenson, S. Suresh \& D.J. Wedel (2008). "ASRA Practice Advisory on Neurologic Complications in Regional Anesthesia and Pain Medicine." Regional Anesthesia and Pain Medicine 335 (52008/10//): 404-415

Perez-Castro, R.,S. Patel, Z.V. Garavito-Aguilar, A. Rosenberg, E. Recio-Pinto, J. Zhang, T.J. Blanck \& F. Xu (2009). "Cytotoxicity of local anesthetics in human neuronal cells." Anesth Analg 1083 (3Mar): 997-1007 
Perlas, A. (2010). "Evidence for the use of ultrasound in neuraxial blocks." Reg Anesth Pain Med 352 Suppl (2 SupplMar-Apr): S43-46

Pollock, J.E. (2003). "Neurotoxicity of intrathecal local anaesthetics and transient neurological symptoms." Best Practice E Research Clinical Anaesthesiology 173 (3: 471484

Pong, R.P., B.S. Gmelch \& C.M. Bernards (2009). "Does a paresthesia during spinal needle insertion indicate intrathecal needle placement?" Reg Anesth Pain Med 341 (1JanFeb): 29-32

Spiegel, J.E., A. Vasudevan, Y. Li \& P.E. Hess (2009). "A randomized prospective study comparing two flexible epidural catheters for labour analgesia." Br J Anaesth 1033 (3Sep): 400-405

van den Berg, A.A., S. Ghatge, G. Armendariz, D. Cornelius \& S. Wang (2011). "Responses to dural puncture during institution of combined spinal-epidural analgesia: a comparison of 27 gauge pencil-point and 27 gauge cutting-edge needles." Anaesth Intensive Care 392 (2Mar): 247-251

van den Berg, A.A., M. Sadek, S. Swanson \& S. Ghatge (2005). "Epidural injection of lidocaine reduces the response to dural puncture accompanying spinal needle insertion when performing combined spinal-epidural anesthesia." Anesth Analg 1013 (3Sep): 882-885, table of contents

van Zundert, A.A., G. Stultiens, J.J. Jakimowicz, D. Peek, W.G. van der Ham, H.H. Korsten \& J.A. Wildsmith (2007). "Laparoscopic cholecystectomy under segmental thoracic spinal anaesthesia: a feasibility study." Br J Anaesth 985 (5May): 682-686

Warren, D., Liu SS (2008). Neuraxial anesthesia in Anesthesiology. B. D. DE Longnecker, Newman MF , Zapol WM,978-1008,The McGraw-Hill Companies, ISBN 978007 148995 9,New York, USA

Watts, S.A. \& D.J. Sharma (2007). "Long-term neurological complications associated with surgery and peripheral nerve blockade: outcomes after 1065 consecutive blocks." Anaesth Intensive Care 351 (1Feb): 24-31

Wedel, D.J., Horlocker T.T (2008). Peripheral nerve blocks in Anesthesiology. B. D. D. E Longnecker, Newman MF , Zapol WM,1025-1052,The McGraw-Hill Companies, ISBN 978007148995 9,New York, USA

Zaric, D. \& N.L. Pace (2009). "Transient neurologic symptoms (TNS) following spinal anaesthesia with lidocaine versus other local anaesthetics." Cochrane Database Syst Rev2 (2: CD003006

Zink, W. \& B.M. Graf (2003). "[Toxicology of local anesthetics. Clinical, therapeutic and pathological mechanisms]." Anaesthesist 5212 (12Dec): 1102-1123 


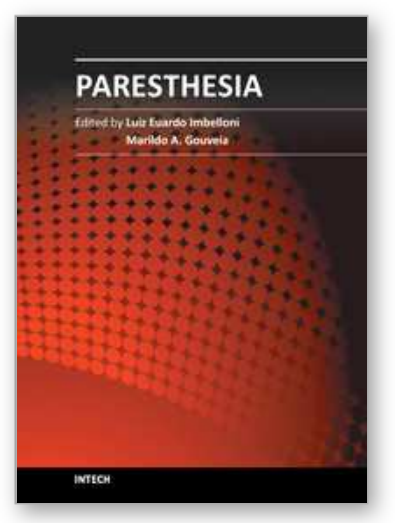

\author{
Paresthesia \\ Edited by Dr. Luiz Eduardo Imbelloni
}

ISBN 978-953-51-0085-0

Hard cover, 90 pages

Publisher InTech

Published online 29, February, 2012

Published in print edition February, 2012

Paresthesias are spontaneous or evoked abnormal sensations of tingling, burning, pricking, or numbness of a person's skin with no apparent long-term physical effect. Patients generally describe a lancinating or burning pain, often associated with allodynia and hyperalgesia. The manifestation of paresthesia can be transient or chronic. Transient paresthesia can be a symptom of hyperventilation syndrome or a panic attack, and chronic paresthesia can be a result of poor circulation, nerve irritation, neuropathy, or many other conditions and causes. This book is written by authors that are respected in their countries as well as worldwide. Each chapter is written so that everyone can understand, treat and improve the lives of each patient.

\title{
How to reference
}

In order to correctly reference this scholarly work, feel free to copy and paste the following:

Bouman Esther, Gramke Hans-Fritz and Marcus A. Marco (2012). Paraesthesia in Regional Anaesthesia, Paresthesia, Dr. Luiz Eduardo Imbelloni (Ed.), ISBN: 978-953-51-0085-0, InTech, Available from: http://www.intechopen.com/books/paresthesia/paraesthesia-in-regional-anesthesia

\section{INTECH}

open science | open minds

\section{InTech Europe}

University Campus STeP Ri

Slavka Krautzeka 83/A

51000 Rijeka, Croatia

Phone: +385 (51) 770447

Fax: +385 (51) 686166

www.intechopen.com

\section{InTech China}

Unit 405, Office Block, Hotel Equatorial Shanghai

No.65, Yan An Road (West), Shanghai, 200040, China

中国上海市延安西路65号上海国际贵都大饭店办公楼 405 单元

Phone: +86-21-62489820

Fax: +86-21-62489821 
(C) 2012 The Author(s). Licensee IntechOpen. This is an open access article distributed under the terms of the Creative Commons Attribution 3.0 License, which permits unrestricted use, distribution, and reproduction in any medium, provided the original work is properly cited. 